\title{
Acceso a la justicia de la mujer migrante en el distrito de Sicaya
}

\section{Access to justice for migrant women in the Sicaya district}

\author{
aAredondo Baquerizo, F; Romero Sihuay, C. \\ Facultad de Antropología / Universidad Nacional del Centro del Perú \\ Email: farredondo@uncp.edu.pe
}

\section{Resumen}

La investigación tuvo como objetivo general, analizar los elementos que conforman la discriminación en el acceso de las mujeres migrantes a la justicia en el distrito de Sicaya. Se utilizó el enfoque mixto: cualitativo/cuantitativo y el método hermenéutico, a través de entrevistas y la interpretación de los testimonios; se encuestó a 50 mujeres migrantes del distrito que han tenido contacto con la justicia en la localidad, directa o indirectamente, a través de amistades o familiares.

Los datos obtenidos se interpretaron en relación con las teorías de migración, género y discriminación, acerca del tema. Los resultados muestran que el acceso de la mujer migrante a la justicia está limitada por diversos factores. Los factores culturales encontrados son el lingüístico y el tipo de vestimenta; los factores sociales son profesionalización de las personas, el tipo de trabajo y prestigio social; por último, entre los factores económicos se encuentran la riqueza y la discriminación por género.

Palabras clave: discriminación sociocultural, acceso a la justicia, migración femenina, equidad de género, grupo étnico

\begin{abstract}
The research had as a general objective to analyze the elements that constitute the discrimination in the access to justice of the women migrants in Sicaya district. The qualitative/ quantitative, and the hermeneutic method were used through interviews and the interpretation of the testimonies; we surveyed 50 women migrants from the distric who have had contact with the local justice system directly or indirectly through family members or friendships.

The data obtained was interpreted in relation to the theories of migration, gender and discrimination that exist about the subject. The results show that the migrants women to the justice is limited by various factors. The cultural aspects found are the linguistic and the type of dressing; the social aspects are the people professionalization, the type of job and the social prestige; finally, betwen the economics aspects are found wealthy and the gender discrimination.
\end{abstract}

Keywords: sociocultural discrimination, access to justice, female migration, gender equality, ethnic group 


\section{Introducción}

El Estado peruano tiene la obligación de garantizar los derechos civiles y la igualdad de las personas frente a la ley y a la justicia (principio de imparcialidad); sin embargo, a pesar que este hecho es contemplado expresamente en la Constitución Política del Estado Peruano, artículo 2, inc.) 2 donde literalmente se señala que: "Toda persona tiene derecho, a la igualdad ante la ley. Nadie debe ser discriminado por motivo de origen, raza, sexo, idioma, religión, opinión, condición económica o de cualquier índole". En la vida real se percibe y demuestra lo contrario. La justicia peruana atiende los requerimientos de las personas tomando en cuenta varios aspectos.

La justicia es un concepto abstracto que esta encarnado en personas que son autoridades y que cumplen la función jurisdiccional de acuerdo a normas y leyes en la sociedad peruana. Los ciudadanos que se ven afectados en sus derechos acuden a la Policía Nacional (policías), al Ministerio Público (fiscales) y el Poder Judicial (jueces en todas sus instancias); además, existe todo un aparato administrativo detrás en estas instituciones encargadas de procesar las denuncias y demandas.

La sociedad peruana es una colectividad estamentaria, jerarquizada donde a cada persona se le ubica en los espacios públicos de acuerdo a ciertos aspectos, como: clase social, género, grupo étnico, apellido, opción sexual y, hasta elementos temporales como la vestimenta, las redes sociales y familiares. Esta situación, también, es funcional en el trato que las personas reciben cuando solicitan servicios que prestan organizaciones públicas y privadas.

El acceso a la justicia, que brinda el Estado, no es ajeno a este hecho, los ciudadanos peruanos reciben el trato en relación directa a su posición social y económica (clase social), al género y sexualidad, de acuerdo a la categoría del patriarcado propuesto por el feminismo el hombre tiene dominio en los espacios públicos en desmedro de las mujeres, en la sociedad hay mucha homofobia, entonces las denuncia de los homosexuales no se toman con seriedad, el Perú es un país multicultural, donde prevalece un grupo cultural sobre los demás, hay una cultura hegemónica que pretende tener el dominio sobre otros grupos subalternos, este grupo tiene privilegios económicos y sociales, por ende en la justicia.

A las categorías de género y etnicidad hay que añadir el de migración, donde personas y grupos sociales se desplazan de un lugar a otro, emigran temporalmente o definitivamente dentro del país a un territorio extranjero, buscando mejoras en sus vidas, siendo discriminadas, simplemente por el hecho que no han nacido en ese lugar; los del lugar, se sienten con mayores derechos que los inmigrantes, reciben mal a los migrantes y los responsabilizan de todo lo negativo que sucede en la comunidad.

La investigación está centrada principalmente en tres de los aspectos señalados; género, grupo étnico y migración.
Respecto al primero, existen dos categorías que definen la situación de relaciones de género en nuestra sociedad, el patriarcado y el machismo que conlleva a la discriminación. Sobre el grupo étnico, se tiene que tomar en cuenta el multiculturalismo, el racismo y la discriminación existente. En relación a la migración, se repite la discriminación como elemento más visible. Si unimos los tres factores se puede apreciar una triple discriminación de la mujer migrante, así como la existencia de barreras lingüísticas en su acceso a la justicia, el poder judicial, y todo su aparato, atiende preferentemente en español y no considera que existan personas que hablan otros idiomas; además, hay un comportamiento de rechazo y vergüenza a las personas que hablan quechua, como también barreras de género, especialmente en los casos de violencia de género donde no se atienden oportunamente las denuncias de las mujeres; pero esos dos factores; no actúan aisladamente, sino que a esto se suma el factor social económico, porque las mujeres andinas están ubicadas en los niveles más bajos dentro de ese factor.

El distrito de Sicaya, desde la década del ochenta del siglo pasado, ha recibido migrantes del sur andino debido a los problemas de violencia política que se vivió en la sociedad peruana, estas personas se han trasladado con sus familias y su cultura a diferentes lugares del país, entre estos espacios ocupados está el valle del Mantaro y sus distritos. A estas personas se las discrimina por su condición de migrantes y responsabiliza de los problemas que sucede en el distrito de Sicaya; si hay robos, alcoholismo, problemas con la juventud o violencia, los sicainos responsabilizan de estos hechos a los migrantes. A esta forma de trato se une la discriminación cultural, se les considera como "personas inferiores" por ser provenientes del sur, según algunas conversaciones y vivencias, se les aprecia como ociosos, alcohólicos, antihigiénicos, llenos de hijos, que solo sirven para realizar actividades manuales, peones, entre otros.

El servicio de justicia local (jueces de paz y policías) tampoco es ajeno a este hecho, se nota una parcialización de estas autoridades hacia los sicainos originarios, nacidos en el distrito, de padres y familias sicainas frente a los migrantes.

La desigualdad ante la Ley, constituye un problema, las afectadas no se sienten conformes, hay desconfianza y crítica, lo que constituye un obstáculo para el desarrollo de la sociedad y evitar la violencia.

\section{Métodos y materiales}

Se utilizó materiales de acopio de información, sobre todo la guía de entrevistas, a través de la cual se obtuvo los testimonios de las personas involucradas en el acceso a la justicia en la localidad. El enfoque que se utilizó en la presente investigación fue el mixto: cualitativo / cuantitativo para la obtención de los datos y el método hermenéutico para la interpretación, contrastando con la teoría de migración, discriminación y de género. 


\section{Resultados}

La investigación tuvo como informantes a $50 \mathrm{mu}$ jeres migrantes en el distrito de Sicaya, de las cuales se obtuvo dos características importantes; en primer lugar, el lugar de procedencia, la cual esta detallado en la Tabla 1, siendo el $96 \%$ proveniente del sur Andino (Huancavelica y Ayacucho). Este dato es relevante, porque permite entender la discriminación étnica por su lugar de origen.

Tabla 1

Origen de las mujeres migrantes encuestadas

\begin{tabular}{lcc}
\hline \multicolumn{1}{c}{ Lugar } & Cantidad & \% \\
\hline Huancavelica & 30 & $60 \%$ \\
Ayacucho & 18 & $36 \%$ \\
Concepción & 1 & $2 \%$ \\
Jauja & 1 & $2 \%$ \\
\hline \multicolumn{1}{c}{ Total } & 50 & $100 \%$ \\
\hline
\end{tabular}

Y, como segunda característica, de acuerdo a la información, las ocupaciones de las mujeres migrantes fueron: $80 \%$, se dedica a la agricultura o pastoreo como peones; $10 \%$, tienen tiendas en la localidad; $6 \%$, venden comidas en las esquinas del parque del distrito y; 4 $\%$, se dedican a otros oficios. Estas actividades refleja la situación social y económica de las investigadas.

¿La atención que reciben las personas en el puesto policial y en los juzgados es justa, es igual para todos?

Los resultados sobre la atención recibida, se muestran en la Tabla 2.

Tabla 2

Resultados sobre la percepción de las mujeres en la atención policial y en juzgados

\begin{tabular}{lcc}
\cline { 2 - 3 } & Cantidad & $\%$ \\
\hline NO es igual & 31 & $62 \%$ \\
SI es igual & 19 & $38 \%$ \\
\hline Total & 50 & $100 \%$ \\
\hline
\end{tabular}

¿Por qué crees que NO es igual?

"Yo iba a una jueza, a veces no entendía y de eso me gritaba, pero fui a otro juez, él sí sabe entender y explicar bien”(María, Huancavelica - Pampas, 33, chacra)

" $A$ veces le hace caso a mi esposo (ex esposo), como a veces no pasa a tiempo el dinero de los alimentos de mis hijos"(Tomasa, Huancavelica, 47, casa)

"Porque todo lo ven plata, la justicia no te atiende si no eres importante; además, a las mujeres peor todavía. Tuvimos un problema y fuimos a una jueza que nos trata mal porque hablamos más en quechua, habla bien nos dice" (Carmen, Huancavelica, 40, ama de casa, chacra)
"Cuando hay problemas de terreno, cuando se pasan los linderos, se supone que a mi deben apoyarme, pero como es su conocido le apoyan al otro, le dieron dinero. Eso me paso cuando fui al juez" (Lorenza, Huancavelica, 33, chacra)

¿Crees que hay discriminación y diferenciación cuando se atienden a las personas en el puesto policial y en los juzgados de paz?

Los resultados sobre discriminación, se muestran en la Tabla 3.

Tabla 3

Resultados sobre la percepción de las mujeres en la discriminación policial y en juzgados

\begin{tabular}{lcc}
\cline { 2 - 3 } & Cantidad & $\mathbf{\%}$ \\
\hline NO hay discriminación & 11 & $22 \%$ \\
SI hay discrimiación & 39 & $78 \%$ \\
\hline Total & 50 & $100 \%$ \\
\hline
\end{tabular}

¿Cómo se da la discriminación?

"Nos dicen, discriminan; chutos, llamas, huancavelicanos por ser foráneos nos tratan”(Olga, Huancavelica, 45, casa)

"Cuando hablas quechua y vistes de pollera, de la población es que te miran mal, en la comisaría no"(Olinda, Huancavelica, 40, casa)

"Si se ve la discriminación en sus actos, yo por ejemplo era parte del vaso de leche, pero me sacaron porque piensan que tengo dinero, vivo en casa alquilada y mi negocio es pequeño"(Leyda, Acolla, 36, confección)

"Cuando eres mujer así te dicen; de seguro le habrás hecho algo, o sino dicen para que te habrás conseguido marido" (Carmen, Huancavelica, 40, casa)

"Los sicainos son creídos y nos tratan mal, nos tratan por foráneos, se creen porque trabajamos para ellos”(Renega, Huancavelica, 26, casa).

¿Si no hablas correctamente el español (idioma) o hablas en quechua la atención es igual en los juzgados de paz y en el puesto policial?

Los resultados sobre la influencia del lenguaje, se muestran en la Tabla 4.

Tabla 4

Resultados sobre el lenguaje y su influencia en la atención policial y en juzgados

\begin{tabular}{lcc}
\cline { 2 - 3 } & Cantidad & \% \\
\hline NO es igual & 38 & $76 \%$ \\
SI es igual & 12 & $24 \%$ \\
\hline Total & 50 & $100 \%$ \\
\hline
\end{tabular}

¿Has escuchado de algún policía o algún juez de paz que hable en quechua a los migrantes cuando presentan su denuncia?

Los resultados sobre la respuesta en quechua, se muestran en la Tabla 5 . 
Tabla 5

Resultados sobre el uso de quechua para la atención policial y en juzgados

\begin{tabular}{lcc}
\cline { 2 - 3 } & Cantidad & \% \\
\hline NO he escuchado & 40 & $80 \%$ \\
SI he escuchado & 10 & $20 \%$ \\
\hline Total & 50 & $100 \%$ \\
\hline
\end{tabular}

Testimonios:

"Aquí no, pero en Acoría si, hasta los policías entienden y hablan, a la fuerza tenemos que hablar castellano” (Emiliana, Huancavelica, 50, chacra)

"El juez que le he dicho, hablaba quechua, había también un policía, pero en Huando no acá” (Marleny, Huancavelica, 29 , chacra)

"No saben, son creídos que van a hablar quechua" (Sabina, Huancavelica, 42, chacra)

"Tienes que hablarle bien, sino te gritan" (Lorenza, Huancavelica, 33, chacra)

"De repente, sus papás pudieron ser quechua hablantes, pero ni así hablan y se supone que ese idioma deben dar importancia" (Olga, Concepción, 45, casa)

"Hay policías, hijos de quechua hablantes, hablaban poco, en mi pueblo si he visto"(Silvia, Huancavelica, 32, casa)

¿Siente alguna expresión de incomodidad o de disgusto por parte de las autoridades cuando un migrante va a presentar su queja o denuncia al puesto policial o al juzgado de paz?

Los resultados sobre la percepción de incomodidad, se muestran en la Tabla 6.

Tabla 6

Resultados sobre la percepción de incomodidad o disgusto en la atención policial o juzgados

\begin{tabular}{lcc}
\cline { 2 - 3 } & Cantidad & $\mathbf{\%}$ \\
\hline NO hay incomodidad & 42 & $84 \%$ \\
SI hay incomodidad & 8 & $16 \%$ \\
\hline Total & 50 & $100 \%$ \\
\hline
\end{tabular}

Podrías describir ese gesto:

"Su cara de molestos, no quieren atender con voluntad, me mandan de un lugar para otro" (Tomasa, Huancavelica, 47 , casa)

"Cuando vamos a ellos directamente no, es como dicen bonito te hablan cuando estas alli, pero hablan mal luego" (Nelly, Huancavelica, 30, casa)

"Como si yo apestara, claro no todos los jueces son así, un de ellas me gritaba por eso me fui a otro juez"(Lorenza, Huancavelica, 33, chacra)

"No atienden rápido, vuelve a tal hora, no hay importancia, pasean mucho"(Olga, Concepción, 45, casa)

"No solo en el juez, sino en la calle, estos ñucas, nos dicen"(Silvia, Huancavelica, 32, casa)

¿Crees que la vestimenta (ropa de trabajo, ropa elegante) con la que uno acude a un puesto policial o juzgado de paz influya la buena o mala atención?

Los resultados sobre la influencia de la vestimenta, se muestran en la Tabla 7.

Tabla 7

Resultados sobre la influencia de la vestimenta en la atención policial y de juzgados

\begin{tabular}{lcc}
\cline { 2 - 3 } & Cantidad & \% \\
\hline NO influye & 27 & $54 \%$ \\
SI influye & 23 & $46 \%$ \\
\hline Total & 50 & $100 \%$ \\
\hline
\end{tabular}

¿Por qué crees que la policía y los jueces se fijan en la vestimenta?

"No se fijan, yo ya no uso pollera, uso pantalón, pero nunca he sentido que me ven mal”(Hayde, Ayacucho, 22, casa)

"Por el dinero que uno le puede dar, agilizar la acción"(Olga, Concepción, 45, casa)

"En el juez si a veces iba con mi zapato con barro, es que vivo aquí por barro también, llegaba a su puesto y me hacían limpiar”(Lorenza, Huancavelica, 33, chacra)

"El vestir bien hace que te vean bien, depende de la vestimenta si eres de aquí o migrantes, de esa forma agilizan tu denuncia" (Elizabeth, Huancavelica, 33, casa)

"Por mi vestimenta se dan cuenta que soy de Huancavelica, y empiezan a hablar como si yo apestará” (Rebeca, Huancavelica, 39, chacra)

"Para saber si somos de aquí, de Sicaya, no les gusta que nosotros vivamos en este barrio" (Sabina, Huancavelica, 42 , chacra)

"A veces voy con mi sombrerito, de la chacra, nomás vengo y tengo que esperar, a veces un ratito, me dicen más tarde o mañana” (Carmen, Huancavelica, 40, casa)

"No hacen notar que si se fija, pero en el fondo hasta nos observan por las flores de nuestros sombreros, con eso se dan cuenta que somos de Huancavelica ni importancia nos dan"(Renega, Huancavelica, 29, casa)

"Nos hacen ver si tenemos dinero o no, pero el hecho que nos vistamos de pollera no indica que no tengamos, yo tengo dinero, animales, terrenos" (Yudelinda, Huancavelica, 33, chacra)

¿Cree usted que la justicia es igual para todos, para pobres y ricos o hay diferencia?

Los resultados sobre la percepción de justicia, se muestran en la Tabla 8. 
Tabla 8

Resultados sobre la precepción de justicia considerando el factor económico

\begin{tabular}{lcc}
\cline { 2 - 3 } & Cantidad & \% \\
\hline NO hay diferencia & 15 & $30 \%$ \\
SI hay diferencia & 35 & $70 \%$ \\
\hline Total & 50 & $100 \%$ \\
\hline
\end{tabular}

\section{¿Por qué hay diferencia?}

"Bueno el dinero siempre compra a las personas, hay malos policías y jueces; así como, en las noticias, pero aquí no”(Marleny, Huancavelica, 29, chacra)

"Siempre así las leyes se den a todo, el rico rompe la mano para que las autoridades los favorezcan”(Denisse, Huancavelica, 38, casa)

"El rico tiene conocidos que le ayuda, pagan para que estén a favor de ellos"(Rosalinda, Huancavelica, 48, chacra)

"El dinero manda, el pobre no tiene que va a pagar abogado, hay que trabajar”(Máxima, Huancavelica, 44, casa)

"La ley es igual para todos, pero las autoridades lo ejercen diferente teniendo preferencias, si das dinero vales, la amistad apoya también”(Brigida, Huancavelica, 48, chacra)

"El dinero manda, tienes que darle por debajo para que avance" (Leyda, Huancavelica, 36, confección)

¿Los profesionales tienen mayores posibilidades que un campesino a acceder a la justicia?

La percepción acerca del acceso a justicia para los profesionales, se muestra en la Tabla 9.

Tabla 9

Resultados sobre la percepción de posibilidad de acceso a la justicia por profesionales

\begin{tabular}{lcc}
\cline { 2 - 3 } & Cantidad & $\mathbf{\%}$ \\
\hline NO hay mayores posibilidades & 14 & $28 \%$ \\
SI hay mayores posibilidades & 36 & $72 \%$ \\
\hline Total & 50 & $100 \%$ \\
\hline
\end{tabular}

\section{¿Por qué?}

"La preparación, ellos saben más, y se visten decentes, bien cultos, a ellos les hacen más caso”(Lorenza, Huancavelica, 33, chacra)

"El conocimiento les hace que superen cualquier cosa, saben a dónde ir, y si tienen conocidos más rápido los atienden”(Elizabeth, Huancavelica, 33, casa)

"Se visten bonito, saben y lo más profesionales son los hijos de los sicainos, para ellos hay más preferencia entre ellos se conocen" (Rebeca, Huancavelica, 39, chacra)

"El que maneja terrenos y animales tiene plata, todo le sale a su favor" (Feliciana, Huancavelica, 75, chacra)

¿Ud. cree que la atención en el puesto policial y en los jueces de paz es igual tanto para los varones y las mujeres, o hay preferencias?
Los resultados sobre la distinción por sexo en el acceso a la justicia se muestra en la Tabla 10.

\section{Tabla 10}

Resultados sobre la percepción en acceso a la justicia por distinción de sexo

\begin{tabular}{lcc}
\cline { 2 - 3 } & Cantidad & $\mathbf{\%}$ \\
\hline NO hay distinción & 38 & $76 \%$ \\
SI hay distinción & 12 & $24 \%$ \\
\hline Total & 50 & $100 \%$ \\
\hline
\end{tabular}

\section{¿Cómo se manifiestan esas preferencias?}

"Cuando el varón va le hacen caso más a él, puro policía varón, autoridad varón también”(Nelly, Huancavelica, 30, casa)

"Cuando fui a mi esposo le hacían más caso, la jueza me gritaba a mí, no a él”(Carmen, Huancavelica, 40, casa)

"Para el varón hay más preferencia, cuentan a su manera las cosas” (Tomasa, Huancavelica, 47, casa)

"Mujer - varón se les trata bien, pero rico pobre, alli si hacen diferencia”(Rosalinda, Huancavelica, 48, chacra)

"Para las mujeres por esto de los derechos de la mujer prevalece, se les apoya más”(Olga, Concepción, 45, casa)

"Tratan igual, pero si hay diferencia entre nosotros que venimos de otro lugar con los sicainos netos"(Lorenza, Huancavelica, 33, chacra)

"De todas formas a nosotros las mujeres, las leyes nos amparan más"(Rebeca, Huancavelica, 39, chacra)

"Las mujeres tienen apoyo de todo el Estado, aunque una juez grita a las mujeres cuando llevan sus problemas de pensión de alimentos, ella trata mal a las mujeres jóvenes"(Gladys, Huancavelica, 51, chacra)

\section{Discusión}

\section{Igualdad de atención de las personas en el pues- to policial y en los juzgados de paz}

La mayor parte de las encuestas consideran que la justicia no cumple con su principio de igualdad, las razones que ellas refieren son varias, entre las principales se puede considerar: el tema del dinero, hay diferencia en la posición económica de las personas, el tema de género, los hombres tienen mayor acceso a la administración de la justicia y el tema cultural relacionado con el lenguaje y el idioma, ellas señalan la siguiente frase: "habla bien", lo que conlleva que las personas originaria del distrito opinan que las migrantes no hablan bien; es decir, no hablan correctamente el español.

Estos elementos de inequidad en el acceso a la justicia se consideran como componentes de discriminación. Santos (2014), sobre el tema, refiere que se entiende la discriminación como prácticas que limitan o niegan derechos y oportunidades a ciertos grupos realizando un trato diferenciado a personas o grupos por algún motivo. 
Él considera que existe discriminación en la empleabilidad, en salud, educación, tratos con el Estado y en la vida cotidiana. Sobre los tratos con el Estado, encuentra que los hogares "indígenas” tienen niveles más bajos de acceso a los servicios públicos, así como menores tasas de conclusión de sus trámites.

\section{Diferenciación y discriminación cuando atienden a las personas en el puesto policial y juzgado de paz}

Las encuestadas describen como ellas sienten, perciben y viven la discriminación, uno de los aspectos que resalta es por el lugar de origen, el hecho de haber migrado de otros lugares, preferentemente de Huancavelica, uno de los rasgos que ellas manifiestan es su forma de hablar que es distinta a la de los lugareños, "no hablamos bien, no hablamos como ellos", es lo que señalan, peor aún si ellas se expresan en su lengua materna, las mujeres migrantes del sur andino, son las que mantienen las costumbres de sus pueblos, esto se refleja en su vestimenta, en sus sombreros, en su pollera, y en el uso de su lengua materna, el quechua, mientras que los hombres usas ropas "modernas", son bilingües y de preferencia en los espacios públicos utilizan el español como idioma.

Otro elemento, está referido al aspecto social y económico, las migrantes se emplean como peones en las chacras de los campesinos, la oferta de mano de obra es grande mientras que la demanda a veces es menor, esto se puede observar diariamente en los alrededores de la plaza de toros del distrito, al ser empleadas de los sicainos, ellas indican que sufren discriminación porque "los sicainos son creídos”, ellos las pueden contratar o no; además, cuando les pagan su jornal, notan que dependen de ellos, y los sicainos hacen notar que gracias a ellos, las migrantes tienen trabajo.

La otra forma de discriminación es por género, muchas denuncias de las mujeres están referidas a la violencia de género, por lo cual ellas presentan sus quejas y la respuesta reiterada que reciben es "qué habrás hecho, para que te has conseguido marido". Se percibe a la mujer como culpable de la violencia que sufre, al no cumplir con sus "obligaciones en el hogar"; por ejemplo, atención al esposo y a los hijos. Además, si tiene esposo ella debe soportar todo, entonces para qué se ha buscado marido.

La discriminación también se refleja en los adjetivos y apelativos que usa la población de Sicaya al referirse a los migrantes: ñuca, majta, llucse, chuto, entre otros; asimismo, ociosos, sucios, delincuentes, llenos de hijos o ignorantes, estos insultos lo dicen en forma velada, pero las encuestadas señalan que ellas perciben o escuchan estos insultos. Cuando existe un conflicto, una pelea o discusión, entre un sicaino y un migrante, en ese momento, los insultos son expresados claramente y en voz alta.

$\mathrm{Al}$ respecto, Casal (2005) considera la imparcialidad como esencial para la buena administración de la justi- cia, el juez, como autoridad no debe encontrarse en una relación psicológica o emocional con la causa, porque puede inclinar a favor de uno o en perjuicio de otro, se debe evitar la amistad, enemistad y el parentesco. Este aspecto, considerado como elemento que garantiza una equidad en la administración de la justicia, es controversial. Los estudios dentro de la antropología jurídica consideran que el hecho de que un juez de paz pertenezca al grupo social es una ventaja, por conocer la cultura del lugar y pueda resolver los conflictos de una buena manera; sin embargo, las comunidades son heterogéneas, hay agricultores pobres y ricos, además de los migrantes que son percibidos como el "otro" por los lugareños.

\section{Hablar correctamente en español o hablar en quechua y la atención en el puesto policial y en los juzgados de paz}

Las tres cuartas partes de las encuestadas, señalan que el tratamiento no es igual. El idioma de un grupo social no son solo palabras, frases y oraciones, también conllevan la historia, los valores y los sentimientos de un grupo social; es decir, si se desvaloriza una lengua se denigra una cultura.

Del mismo modo, cuando las personas quechua hablantes son discriminadas por su idioma, por su forma de hablar o no encuentran imparcialidad dentro de los operadores de justicia y, personas que no entiendan su lengua, ellas se sienten desvalorizadas y en desventaja frente a la demanda de justicia. Más aún, cuando en el proceso de socialización en el nuevo lugar donde han migrado, al querer expresarse en español cometen algunas equivocaciones, entonces son identificados rápidamente y discriminados.

Las investigaciones al respecto, consideran que en el país existe una barrera lingüística para el acceso a la justicia, así lo señala La Rosa (2007), para quien la posibilidad de muchos pobladores quechuas, aimaras o de la Amazonía al acceso a la administración se ve reducida, porque los funcionarios de justicia desconocen el idioma nativo y no tienen intérpretes; es decir, se presenta una discriminación lingüística. En el mismo sentido, Howard (2007) indica, respecto al tema lingüístico, que existen dos formas de discriminación, por hablar cierta lengua y por la forma de hablar.

Gugenberger (1997) manifiesta que es poco probable que un quechua hablante de una determinada región hable con otro quechua hablante de otra región, no hay una identidad lingüística supra nacional, a no ser que entre ambas personas exista una gran confianza, por eso se prefiere hablar en castellano, porque hay fronteras dialectales, hay que reconocer que la lengua también es un instrumento de poder. La autora, mediante un experimento entre dos mujeres en un puesto de salud, demostró que se le atiende primero a la mujer que mejor "habla el castellano", a pesar de haber llegado después de otra mujer que solo se expresaba en quechua. 
Sin embargo, en el caso de Sicaya se puede percibir hasta tres; el primero, las que hablan quechua; el segundo, por la forma de hablar, a pesar que Sicaya es una comunidad andina, los lugareños consideran que los migrantes sureños hablan mal el español, hay una fuerte presencia fonética y gramatical de rasgos quechua, y; una tercera, en Sicaya no ha desaparecido completamente el quechua, aún continua hablándose, pero en círculos muy íntimos y familiares, casi no se nota su presencia en espacios públicos, pero el quechua que se habla en la localidad es el wanka en contraposición con el "quechua sureño”, como así lo denominan los propios sicainos, produciéndose otro tipo de marginación y reconocimiento del origen de las personas por el idioma que hablan, sea el quechua wanka o del sur.

Las limitaciones se exteriorizan cuando los migrantes presentan sus quejas o denuncias ante los operadores de justicia, al expresarse los reconocen como migrantes, no los atienden bien, en el caso de la mujeres que se expresan preferentemente en quechua, son discriminadas y no encuentran intérpretes, en estos espacios se evita hablar en el idioma nativo porque esto representa un desprestigio y una vergüenza, Howard (2007) explica este hecho a través del concepto de hegemonía propuesto por Antonio Gramsci, las ideología lingüísticas dominantes se introducen en los hablantes, a través de las instituciones de la sociedad, sean educativas, religiosas y gremiales; además, su influencia se ve fortalecida mediante recompensas y castigos, este hecho se reproduce a nivel macro, instituciones sociales y del Estado, y a nivel micro de intercambios personales.

En Sicaya, se reconoce una correcta manera de hablar, se considera correcta cuanto más cercana está las expresiones al idioma oficial, el castellano; de igual modo, funciona en sentido contrario más lejana al idioma oficial, más incorrecta. Lo cual influye en la percepción como individuo y la atención en los servicios que brinda el Estado.

\section{Policías o jueces de paz que hablan quechua en sus lugares de atención}

Las encuestadas señalan que las autoridades no hablan quechua, "son creídos, que van hablar quechua" interpretando este mensaje se puede considerar que hablar este idioma denigra a la persona que lo practica, las sitúa en condiciones de inferioridad en las relaciones sociales del distrito, las informantes indican que en sus lugares de origen, Huancavelica, si habían autoridades que hablaban quechua, ya sea policías o jueces, este hecho a ellas las hacía sentir en confianza y percibían que podían encontrar justicia.

Al respecto, Ardito (2010) señala que en el Perú existe un monolingüismo estatal, lo que ha provocado que millones de personas no tengan acceso a la admi- nistración de justicia; según el autor, existe aproximadamente siete millones de quechua hablantes y las normas oficiales del Estado siguen emitiéndose en castellano, también indica que las autoridades encargadas de recibir las denuncias o demandas no hablan quechua, aunque, manifiesta que los jueces de paz están obligados a saber quechua en concordancia con la Ley $\mathrm{N}^{\circ} 28545$.

Otro aspecto importante a la que se refiere Ardito (2010), es el temor de las personas a expresarse en quechua por miedo a que las autoridades los menosprecien; además, que según la experiencia del autor existen jueces, policías y autoridades que hablan quechua; pero, prefieren no hablar en este idioma porque los idiomas tienen espacios especiales de uso, el quechua solo se utiliza en espacios familiares, amicales y de confianza, mientras que el castellano se utiliza en espacios públicos. Finalmente, apunta que hay un gran esfuerzo por parte de Ministerio de Justicia que ha elaborado versiones de la Constitución Política del Estado en idioma quechua y aimara.

Respecto a los espacios idiomáticos, ya lo había afirmado Ortíz (1998), cuando señala que el indio habla quechua en la intimidad del hogar, con sus hijos, con su pareja, mientras que en la calle y en la ciudad se transforma en hispano hablante, el antropólogo acuña el término espacios idiomáticos para explicar esta situación lo realiza para evitar ser discriminado.

\section{Expresiones o gestos de incomodidad de poli- cías o jueces de paz cuando los migrantes pre- sentan sus denuncias o quejas}

De acuerdo con la encuesta no hay incomodidad, solo el $16 \%$ percibe incomodidad, pero de acuerdo con los testimonios, ellas perciben la molestia de las autoridades cuando van a presentar sus denuncias y quejas, plantean que hay un maltrato desde la indiferencia hasta los gritos. Un testimonio señala que estas actitudes antes eran peor, con las primeras migrantes en la década del 80 del siglo pasado, se repiten los testimonios que manifiestan la superioridad con que se asumen los lugareños frente a los migrantes, los sicainos ven como inferiores a los migrantes, por eso los gestos despectivos hacia ellos, así como los insultos, "ñucas". Una informantes indica que se demoran en atenderlas, "nos pasean", también perciben hipocresía en las autoridades cuando estas delante de ellos te hablan bien, pero en las espaldas hablan mal.

De acuerdo a la sociología y antropología, el cuerpo al igual que la lengua es un constante proveedor de significados; así lo plantea Le Breton (2006), las personas perciben e interpretan la información que recibe del exterior, el individuo descifra los datos que lo rodean, es así que descifra gestos de acuerdo a su entorno cultural, los cuerpos emiten gestos de agrado, desagrado, a través de las miradas, movimientos del rostro, sonrisas y movimientos corporales. 
Los migrantes que acuden a presentar sus denuncias o demandas en el puesto policial o en los juzgados de paz del distrito perciben que no los tratan bien; "nos ven mal", "piensan que no nos damos cuenta, pero sabemos", "hablan mal de nosotras, entre ellos", son algunas expresiones de las migrantes.

$\mathrm{Al}$ respecto, Goffman (2012) señala que los funcionarios de un Estado que alcancen una jerarquía importante adoptan un comportamiento distinto a la clase que pertenece, generalmente adopta la actitud de la clase dominante, trata de copiar el estilo de vida y las actitudes de la clase referida; por otro lado, el autor también indica que cuando una persona llega a entablar un tipo de relación con otra busca toda la información posible sobre esta persona con el objeto de saber cómo actuar frente a ella. Para recabar esta información, se sirve de la apreciación directa y los indicios que pueda transmitir la persona.

Mauss (1971) hace una análisis antropológico de los gestos relacionados con la magia; sin embargo, en la última parte de su publicación hace referencia al tema psicológico y subjetivo, indicando que la visa social es un mundo de relaciones simbólicas donde el lenguaje y el gesto desempeña un papel fundamental.

La vestimenta, indumentaria influye en la atención en el puesto policial y en los juzgados de paz

El $54 \%$ de los encuestados señalan que la vestimenta no influye en la atención que puedan recibir, este hecho se debe a que Sicaya es un distrito donde la actividad principal es la agricultura seguida de la ganadería, por lo cual, la mayor parte de la población se desplaza en espacios públicos y en el campo con ropa de trabajo; además, los pobladores se conocen entre ellos y no necesitan estar bien vestidos para que este hecho influya en las autoridades, pues estos identifican a los sicaínos y a los migrantes. Sin embargo, cuando una persona esta vestida "correctamente" (si es posible con terno o un traje) entonces va a recibir una mayor atención de las autoridades.

Brevemente, Ardito (2010) indica que la ropa actúa como un elemento externo para enfatizar las diferencias y para poder discriminar a las personas.

Schwarz (1976) contempla varias funciones para el vestido, dentro de ellas está la del estatus y de la posición social, la de distinguir a las individuos de un grupo social por la clase social y el rango social a la que pertenecen.

Harris (2004) manifiesta que la vestimenta, en las sociedades estratificadas, sirve para reconocer a las personas a que estamento o clase pertenecen, incluso si una persona usaba ropas que no correspondían a su sector social podía ser ejecutada.

Friedman (2001) afirma que la distinción se ajusta perfectamente al Congo, allí la vestimenta es determinante en la práctica de la diferenciación social, pone como ejemplo espacios como la iglesia, cementerio o la morgue, donde se aprecia la elegancia de los atavíos y de la exquisitez por el gusto.

Dentro de las investigaciones de las ciencias sociales se considera que la vestimenta, es un elemento externo, que te jerarquiza. Sicaya no es un distrito homogéneo, un elemento que visibiliza al pobre, o a la mujer migrante.

\section{Los policías y los jueces se fijan en la indumen- taria de los usuarios}

La vestimenta es un elemento identitario, sobretodo en las mujeres que son las que mantienen la vestimenta tradicional de sus pueblos de origen, entonces es fácil identificar el origen de una persona solo observando su ropa: pollera, lliclla, sombrero y otros. Ellas están paradas o sentadas junto a sus menores hijos en los juzgados, se aprecia su vestimenta típica, polleras, medias de lana, una chompa abierta, generalmente de colores muy llamativos, amarillas, celestes, rosado, las trenzas y un sombrero pequeño a veces adornado con una flor. Esta indumentaria se diferencia de la vestimenta considerada típica de las sicainas, entonces es sencillo diferenciar quién ha nacido en el distrito y quién ha venido de otro lugar, solo con observar.

Degregori (2014) señala que la lengua y el vestido tradicional son dos elementos visibles por la que los indios eran reconocidos y despreciados, (elementos culturales antes que raciales), según el autor, son dos elementos que los migrantes han tenido que sacrificar al migrar a la capital del país para evitar la discriminación. En Sicaya este hecho no se repite mecánicamente, al ser el distrito también andino; de alguna manera, se mantiene el quechua wanka, el aspecto de la vestimenta, se mantiene, preferentemente en las mujeres. Aunque en los hijos y las hijas de los migrantes van adoptando indumentaria considerada occidental por su acceso a la educación superior y trabajos en la ciudad de Huancayo.

Valdivia (2012), respecto al servicio de salud que brinda el Estado, en una simulación, (técnica del paciente simulado) encontró que las pacientes ataviadas con polleras y quechua hablantes recibieron de las profesionales de salud, obstetras, un trato paternalista, autoritario y afectuoso, a la vez que se refiere a la paciente en términos de "mamita", también rezondra y llama la atención; según el investigador, no existe una clara discriminación, sino un paternalismo vertical donde el paciente tiene el papel de menor de edad a quien se le puede llamar la atención severamente.

A través de la encuesta, los testimonios señalan que la discriminación no se presenta en la vestimenta porque la mayoría en el distrito se desplaza en ropa de trabajo, en ropa de campo, van a la chacra; sin embargo, cuando acudes al puesto policial o a los jueces de paz, con el vestido tradicional de las regiones del sur si se presenta la discriminación, las migrantes perciben que por su indumentaria reciben mala atención "nos hacen esperar en 
la calle", "nos sentamos en la tierra, con nuestros hijos", "cuando entramos en la oficina ni nos miran", "nos gritan", "nos llaman la atención fuertemente”.

\section{El acceso a la justicia diferencia entre pobres y ricos}

Un porcentaje considera que si hay diferencia (70 $\%)$, uno de los elementos que las entrevistas consideran es mayores redes sociales que manejan los ricos, mientras que los pobres no, es decir, los ricos tienen más paisanos, amigos y conocidos, los pobres no, sobre todo en un distrito de los andes, este hecho culturalmente tiene más trascendencias. Otro argumento que toman en cuentas las encuestadas es que el "dinero manda", las que tienen dinero son "mejor atendidas”, son preferidas, sobre todo en el distrito donde a decir de los antropólogos clásicos, es un espacio donde todos se conocen y reconocen, saben quién tiene dinero y quién no. Un elemento que se repite en los espacios administrativos públicos y sobre todo en la administración de justicia del país es la corrupción, "romper la mano a las autoridades", es decir, sobornar, para obtener los favores de las autoridades.

Por último, ellas mismas se asumen como pobres, "no tenemos dinero", entonces las autoridades no nos van a atender adecuadamente, este hecho se puede contrastar con su situación laboral, la mayor parte son peones o pastorean animales, de los sicaínos o de las personas que les pueden pagar su jornal.

Dentro de las ciencias sociales existen categorías, como sociedades complejas y simples, que aún se utilizan en las investigaciones; en las primeras, se ubican grandes ciudades, industria, gran comercio y personas con gran acceso adquisitivo, son sociedades con una gran heterogeneidad social y; en las sociedades simples, hay una economía primaria y de subsistencia, estáticas y homogéneas socialmente así se puede encontrar en las miradas de los investigadores de la capital. Para Kogan (2012) el poder, el prestigio y la riqueza se articulan de tal modo que sabemos quién es quién, quién manda y quién tiene más riqueza.

Las características, que la autora menciona, las podemos encontrar en Sicaya, personas, familias que ostentan el poder unido con el prestigio y la riqueza, el poder claramente representado en los cargos de autoridades, el prestigio en el respeto que representa para la fiesta patronal, tener un hijo profesional, vivir en el extranjero, ser un exitoso comerciante, profesional entre otros, la riqueza no solo conlleva el número y extensión de terrenos de cultivo dentro y fuera de la comunidad, bienes inmuebles y muebles, entre otros, es una sociedad completamente heterogénea y donde sí se conoce quién es quién, quién manda y quién tiene más riqueza.

Esta diferenciación económica establece claras jerarquías al recibir los servicios de justicia brindados por el Estado. "La plata lo soluciona todo", "le pasan por debajo al policía”, "con la plata están felices”.

\section{Los profesionales tienen mayores posibilidades en el acceso a la justicia}

El tema de acceder a la educación formal es importante para las personas, estudiar escuela, colegio y luego universidad, ser profesional, trabajar como profesional, trabajar en una institución pública o privada, tener dinero, vestir bien, gastar en las reuniones sociales, son aspectos que dan prestigio social y te ubican en un lugar adecuado en la jerarquía social para acceder a bienes y servicios, como la justicia; por eso, el $72 \%$ de las encuestadas consideran que los profesionales tienen mayores posibilidades de acceder a la justicia. Mientras que ser "ignorante" (no haber accedido a la educación oficial), analfabeta limita tus oportunidades en el acceso a la justicia.

Esta pregunta sirvió para corroborar la pregunta ocho, los testimonios refuerzan lo anterior; según las encuestadas, si uno tiene educación no puede ser engañado, puede ser humillado, saben comportarse y actuar, tienen habilidad o son cultos. A través de estas respuestas se puede apreciar que la educación oficial no solo se circunscribe al tema económico, posible éxito económico, sino, trasciende al ámbito social y cultural, una especie de capital simbólico como lo plantea Bourdieu. Aunque también, se sigue haciendo énfasis en el tema económico como tener chacras, terrenos y animales, estas posesiones favorecen al momento de buscar justicia, "todo sale a su favor".

Degregori (2014) indica sobre el concepto de progreso, donde las personas andinas creen poder alcanzar mediante la educación. Para el hombre andino hay elementos que le permitirán salir de una situación postergada, estos son: la escuela, el comercio y el trabajo asalariado.

Esto refleja la preocupación de los migrantes de enviar a sus hijos a la escuela, colegio y universidad de acuerdo a sus posibilidades, incluso haciendo algunos sacrificios.

Tener una título profesional te ubica en un estatus superior, es un orgullo para la familia, se puede apreciar a los familiares acompañar a sus hijos e hijas en los actos de sustentación y defensa de sus tesis, celebrar en las graduaciones. Las personas del valle del Mantaro, consideran el título profesional como un gran logro no solo a nivel social, sino que redundará en el aspecto económico.

\section{La atención en el puesto policial y en los juzgados de paz es igual o diferente para hombres y mujeres}

Las encuestadas, en forma mayoritaria (76\%), manifiestan que no hay preferencia en la atención según el género; es decir, consideran la justicia imparcial e, incluso a través de los testimonios, indican que ahora ellas tienen más ventaja sobres los hombres en el acceso a la justicia. Incluso concuerdan que ahora (en los últimos años) les favorece las leyes a ellas sobre sus parejas, "todo el apoyo para las mujeres del Estado", "aunque no tengan razón”, han escuchado sobre los derechos de las mujeres y esto hace que refuercen sus convicciones. 
Aunque hay que tener en cuenta también lo que plantea Bourdieu (1999) sobre la violencia simbólica, cuando la víctima asume la posición del victimario, es decir, la mujer acepta el punto de vista del hombre respecto a diversos aspectos de su opresión, y hasta se siente cómoda, como en el acceso de ella a la justicia que la considera hasta exagerado su atención en contraste con la del hombre.

A través de la investigación, y la contrastación con la teoría, se encontró que la clásica discriminación en el acceso a la justicia no solo revista el tema de género, mujeres, el aspecto étnico, cultural (vestimenta, idioma), ni el aspecto socio económico, pobreza. Valverde (2013) manifiesta que en el caso de las mujeres migrantes se presenta una triple discriminación; por ser mujer, trabajadora y migrante. Mientras que para el caso de Sicaya (acceso a la justicia) se puede identificar los tres elementos, la triple discriminación, aunque hay un cuarto elemento, la migración.

Dentro de la teoría referida a la construcción de la identidad, sentido de pertenencia. Vich (2001), citando a Lacan, indica que el sujeto no puede constituirse sin la imaginación del Otro que es descrito en términos amenazantes. Es decir, la existencia del sicaino se concretiza cuando está en relación con otro grupo social; en este caso, los migrantes sureños, a los que se los percibe dentro de espectro negativo; sucios, ignorantes, ociosos, pleitistas, delincuentes y, en contrapartida, ellos se sitúan en una posición positiva.

En ese sentido, al otro, incluso se le deshumaniza. Al llegar a este punto, se le puede agredir y hasta asesinar, tal como lo indica Maalouf (2016). Hay personas que cometen crímenes en nombre de su identidad religiosa, étnica, nacional o de otra naturaleza. La identidad de una persona está definida por una infinidad de elementos; pertenencia a una nación, a una religión, a un grupo étnico - lingüístico, a una familia, profesión, institución y ámbito social.

\section{Conclusiones}

- Las mujeres migrantes del distrito de Sicaya tienen limitaciones en el acceso a la justicia por el idioma, ellas al expresarse en su lengua materna, no encuentran operadores de justicia (policías, jueces de paz) con quienes puedan conversar en el idioma referido, incluso, culturalmente, las personas creen que hay una forma correcta de hablar en la comunidad de la cual están excluidas las migrantes. Ellas perciben gestos de desagrado y expresiones de incomodidad que en los lugares públicos donde acuden a entablar sus quejas y denuncias.

- La vestimenta no tiene mucha influencia en el acceso a la justicia, porque en el distrito las personas se dedican a actividades agropecuarias y generalmente transitan con ropa de trabajo; sin embargo, la vestimenta tradicional femenina de las migrantes del sur andino es notoria y genera discriminación, así como su origen lo que se refleja en algunos insultos que ellas reciben.

- En relación a los ingresos económicos, ellas indican que el dinero posibilita que puedan tener una buena atención en el puesto policial y en los juzgados de paz, hasta contando con dinero puedes corromper a las autoridades. Respecto a la educación formal, señalan que los profesionales no se dejan engañar, conocen sus derechos y pueden reclamar.

- Sobre la discriminación por género, indican que las mujeres en la actualidad están en ventaja frente a los hombres, ellas tienen mejor atención que sus parejas, porque incluso los denuncian "por gusto", sus derechos están mejor salvaguardados por el Estado.

\section{Referencias bibliográficas}

Ardito, W. (2010). La promoción del acceso a la justicia en las zonas rurales. (tesis de doctorado) PUCP, Lima - Perú.

Benavides, M. (2015). Violencia familiar y acceso a la justicia en el mundo rural: estudio de cuatro comunidades. $1^{\circ}$ ed. Lima - Perú. Edit. GRADE.

Bourdieu, P. (1999). La dominación masculina.

Casal, J. (2005). Derechos humanos, equidad y acceso a la justicia. $1^{\circ}$ ed. Caracas - Venezuela. Edit. Instituto Latinoamericano de Investigaciones Sociales.

Degregori, C. (2014). Del mito del Inkarri al mito del progreso: poblaciones andinas, cultura e identidad social. Cambios culturales en el Perú. $1^{\circ}$ ed. Lima-Perú. Edit. Ministerio de Cultura.

Friedman, J. (2001). Identidad cultural y proceso global. 1ra. ed. Buenos Aires. Ed. Amorrortu.

Goffman, E. (2012). La presentación de la persona en la vida cotidiana. 1ra. Ed. Buenos Aires. Ed. Amorrortu.

Golte, J. y Adams, N. (1987). Los caballos de Troya de los invasores. Estrategias campesinas en la conquista de la gran Lima. $1^{a}$ ed. Lima-Perú. Instituto de Estudios peruanos.

Hernández, R.; Fernández, C. y Baptista, P. (2010). Metodología de la investigación. México D.F. Edit. Mc Graw Hill.

Harris, M. (2004). Introducción a la antropología general. 7ma ed. España. Ed Alianza. Howard, R. (2007) Por los linderos de la lengua. Ideologías lingüísticas en los Andes. 1ra ed. Lima, Perú: IEP.

Kogan, L. (2012). Desestabilizar el racismo: el silencio cognitivo y el caos semántico, en la discriminación en el Perú. Balances y desafíos. $1^{\circ}$ ed. Lima - Perú. Edit. Universidad de Lima.

La Rosa, J. (2007). Acceso a la justicia: elementos para incorporar un enfoque integral de política pública. En 
Acceso a la justicia en el mundo rural. Ed. Lima Perú. Instituto de Defensa Legal.

Le Breton, (2007). El sabor del mundo. Una antropología de los sentidos. 1 ed. Buenos Aires. Ed. Nueva Visión.

Mauss. M. (1971). Sociología y Antropología. $1^{\circ}$ ed. Madrid. Ed. Tecnos.

Maalouf, A. (2016). Identidades asesinas. $6^{\circ} \mathrm{ed}$. España. Ed. Alianza editorial.

Ortíz, A. (1998). Sobre la persona y la pareja andina. 1ed. Lima - Perú. Ed, PUCP

Santos, M. (2014). La discriminación racial, étnica y social en el Perú: balance crítico de la evidencia empírica reciente. De- bates en Sociología $\mathrm{N}^{\circ}$ 39. Lima - Perú. Ed: PUCP

Valdivia, N. (2012). La discriminación en el Perú y el caso de los servicios de salud resultados de un estudio cualitativo en el valle del Mantaro. En La discriminación en el Perú. Balances y desafíos. $1^{\circ}$ ed. Lima - Perú. Edit. Universidad de Lima.

Valverde, A. (2013) Inmigración extranjera desde una perspectiva de género. El caso gallego. [tesis]. [Madrid]: Universidad Complutense.

Vich, V. (2001). Sobre cultura, heterogeneidad, diferencia. En Estudios culturales. Discursos, poderes, pulsiones, $1^{\circ}$ ed. Lima - Perú. Edit. Universidad de Lima. Edit. Red para el desarrollo de las ciencias sociales en el Perú. 